\title{
Comparisons between Chinese and Mongolian Patient Satisfaction
}

\author{
Na Chen'1, Xinxing Zhou ${ }^{2}$, Yingkui Zhang1* \\ ${ }^{1}$ School of Economics and Management, Beijing University of Chemical Technology, Beijing, China \\ ${ }^{2}$ Longmaster Information \& Technology Co. Ltd., Guiyang, China \\ Email: chenn4@163.com, xinxing.zhou@longmaster.com.cn, ${ }^{\star}$ zhangyk@mail.buct.edu.cn
}

How to cite this paper: Chen, N., Zhou, $\mathrm{X}$. X., \& Zhang, Y. K. (2017). Comparisons between Chinese and Mongolian Patient Satisfaction. Psychology, 8, 2126-2137. https://doi.org/10.4236/psych.2017.813135

Received: November 2, 2017

Accepted: November 19, 2017

Published: November 22, 2017

Copyright (c) 2017 by authors and Scientific Research Publishing Inc. This work is licensed under the Creative Commons Attribution International License (CC BY 4.0).

http://creativecommons.org/licenses/by/4.0/

\section{c) (i) Open Access}

\begin{abstract}
This study compared the differences between Chinese and Mongolian patient satisfaction and investigated factors influencing patient satisfaction of the two countries in order to provide suggestions for the establishment and improvement of Mongolia's health care system. This study involved two questionnaire surveys. Questionnaire Survey I investigated patient satisfaction of the two countries, whereas based on the first survey, Questionnaire Survey II revisited the respondents and investigated the reasons for their dissatisfaction with different aspects of health care service. According to the results of Questionnaire Survey I, Chinese overall patient satisfaction was higher than that of Mongolian. China and Mongolia had their own advantages in different health care service aspects respectively. The factors of consideration, cost of care and quality/competence showed significant influences on Chinese patient satisfaction, whereas the factors of hospitals, payment mechanisms and quality/competence showed significant influences on Mongolian patient satisfaction. According to the results of Questionnaire Survey II, Chinese individuals were more likely to express their dissatisfaction. Chinese individuals' dissatisfaction focused on the issues of high costs of seeing a doctor, long waiting time and unreasonable procedures, whereas Mongolian individuals' dissatisfaction focused on the issues of long waiting time, high costs of seeing a doctor and doctors' poor attitudes. Implications were discussed for the development of Mongolia's health care system.
\end{abstract}

\section{Keywords}

Patient Satisfaction, Health Care, China, Mongolia

\section{Introduction}

Mongolia is an important neighbor of China. With the launch of The Belt and 
Road Initiative, the communication between China and Mongolia is increasing gradually. China has remained the position of Mongolia's largest trading partner for more than 10 years (Yang, 2017). With the deepening of communication, China and Mongolia have strengthened the exchanges and cooperation in the health care field (Ministry of Foreign Affairs of the People's Republic of China, 2015). China has exported electronic medical equipment and sent medical teams to Mongolia (A. S. G., 2017).

There is a lack of academic researches related to the health care system in Mongolia. According to the government document, Mongolian medical technology level keeps average; medical facilities need to be improved; medical supplies mainly rely on imports from foreign countries; the numbers of professional medical staff are inefficient (Chinese Academy of International Trade and Economic Cooperation et al., 2016); this suggests that the demands of Mongolian people have not been satisfied fully. The understanding of Mongolian health care system still needs to be strengthened in order to improve quality of life of Mongolian people. On the other hand, after nearly four decades of the reforms and opening up, China's health care system has developed to a certain stage.

The comparisons between China's and Mongolia's health care system can help China understand the needs of Mongolia in the health care industry better in order to establish more effective cooperation in the health care field, can help Mongolia recognize its advantages and disadvantages in the health care industry in order to improve its health care system, and can help Mongolia learn from the development of China's health care system and predict the problems its system will face in the future.

The research on health care systems can be conducted from multiple perspectives, including hospital quality, health plan quality, physician quality, patient experience and so on. This study investigated from a primary and basic topic in the health care field-patient satisfaction and explored the differences between Chinese and Mongolian individuals. A high-quality health care system requires delivering patient-centered care (Carroll, 2002). Patient satisfaction examines health care services from patients' point of view and determines individuals' perceptions of the quality of health care they received (Tsai, Orav, \& Jha, 2015). Patient satisfaction is usually measured by individuals' self-report questionnaires. The measurement of patient satisfaction investigates patients' experiences of health care, identifies problems in the health care system and evaluates the system (Fitzpatrick, 1984). Recent research related to Chinese patient satisfaction mainly focused on the satisfaction with the health care system in specific regions of China (Li et al., 2016) and factors influencing patient satisfaction (You et al., 2013).

This study aimed to compare the differences of patient satisfaction between China and Mongolia and investigate factors influencing patient satisfaction in the two countries in order to provide suggestions for the establishment and improvement of Mongolia's health care system. This study involved two question- 
naire surveys. The first questionnaire survey investigated patient satisfaction in the two countries, whereas based on the first survey, the second questionnaire survey revisited the respondents and investigated the reasons for their dissatisfaction.

\section{Questionnaire Survey I}

\subsection{Methodology}

Based on the short version of the Patient Satisfaction Questionnaire (PSQ; Ware Jr, Snyder, Wright, \& Davies, 1983), we conducted the first questionnaire survey and compared patient satisfaction of Chinese and Mongolian individuals. We firstly conducted an expert evaluation involved two experts in the health care field. One of them is a senior researcher in the field of experimental psychology and the other holds a doctoral degree in experimental psychology.

The evaluation principle was the scenarios involved in the items reflected the actual situations of Chinese and Mongolian health care systems. Based on the results of the expert evaluation, we screened 31 items from the 43 items in the original questionnaire. These 31 items involved six dimensions, including access to care, financial aspects, availability of resources, technical quality, interpersonal manner, and overall satisfaction. The dimension of access to care includes factors involved in arranging to receive medical care, such as the item "places where you can get medical care are very conveniently located"; the dimension of financial aspects includes factors involved in paying for medical services, such as the item "the amount charged for medical care services is reasonable"; the dimension of availability of resources means the presence of medical care resources, such as the item "there are enough hospitals in this area"; the dimension of technical quality means doctors' competence and their adherence to high standards of diagnosis and treatment, such as the item "doctors aren't as thorough as they should be"; the dimension of interpersonal manner includes the features of the ways in which doctors interact with patients, such as the item "doctors hardly ever explain the patient's medical problems to him". The full questionnaire was listed in Appendix. These dimensions included 13 sub-scales. The numbers of items in these sub-scales are listed in Table 1.

The screening was mainly based on whether the item was consistent with the current status of the health care system conditions in China and Mongolia. For example, the item "I think my doctor's office has everything needed to provided complete medical care" in the original questionnaire was inconsistent with the health care system condition in China; in Chinese hospitals, the examination rooms were usually separated from the doctors' offices. In addition, the item of "there are enough family doctors around here" was inconsistent with the conditions in both China and Mongolia; in the two countries, few people experience the services of family doctors and most people accepted public health care service. The screening also reduced the number of items in order to reduce respondents' fatigue in answering questionnaires. 
Table 1. Meanings of dimensions and sub-scales in each dimension.

\begin{tabular}{ccc}
\hline Dimension & Sub-scale & No. of items \\
\hline \multirow{2}{*}{ Access to care } & Emergency care & 1 \\
& Convenience of services & 2 \\
Financial aspects & Cost of care & 2 \\
& Payment mechanisms & 2 \\
Availability of resources & Insurance coverage & 2 \\
& Specialists & 1 \\
Technical quality & Hospitals & 2 \\
& Quality/competence & 6 \\
Interpersonal manner & Prudence-risks & 1 \\
& Explanations & 2 \\
Overall satisfaction & Consideration & 5 \\
& Prudence-expenses & 1 \\
\hline
\end{tabular}

SPSS 21.0 was used for data analysis in this study.

\subsection{Participants}

We issued the Mongolian version of questionnaires through Facebook in Mongolia and collected 96 valid questionnaires and we collected 98 valid questionnaires in Chinese through WeChat in China. Among them, the Mongolian sample involved 51 female respondents and 45 male respondents and the Chinese sample involved 64 female and 34 male respondents. The average ages were 22.65 years old $(\mathrm{SD}=7.53$; Chinese sample) and 23.51 years old $(\mathrm{SD}=9.48$; Mongolian sample). According to the results of t-tests, there were no significant differences in gender ratios $(t=1.730$, Sig. $=0.085)$ and average ages $(t=-0.697$, Sig. $=0.487)$ between the two samples.

\subsection{Results: Differences between Chinese and Mongolian Patient Satisfaction}

According to the results of independent samples t-test, the overall satisfaction of Chinese respondents was significantly higher than that of Mongolian respondents $(t=9.554$, Sig. $<0.001)$. The Chinese sample showed significant higher satisfaction in the sub-scales of specialists $(\mathrm{t}=15.777$, Sig. $<0.001)$, explanations $(\mathrm{t}$ $=3.062$, Sig. $=0.003)$, hospitals $(t=2.374$, Sig. $=0.019)$, and quality/competence $(t=2.141$, Sig. $=0.034)$ than the Mongolian sample, whereas the latter sample showed significantly higher satisfaction in the sub-scales of consideration $(t=$ -3.506 , Sig. $=0.001)$, convenience of services $(t=-6.558$, Sig. $<0.001)$, cost of care $(t=-26.871$, Sig. $<0.001)$, emergency care $(t=-4.018$, Sig. $<0.001)$, and payment mechanisms $(t=-10.595$, Sig. $<0.001)$ than the former sample. There was no significant difference in the satisfaction in the sub-scales of emergency 
care, prudence-expense, and prudence-risks between the two samples (all Sig. > 0.200). The details of the results are listed in Table 2.

\subsection{Results: Factors Influencing Chinese and Mongolian Patient Satisfaction}

According to the results of a linear regression, the sub-scales of consideration, cost of care and quality/competence showed significant influences on Chinese patient satisfaction, where the subscales of hospitals, payment mechanisms and quality/competence showed significant influences on Mongolian patient satisfaction. The details of the regression testing results are listed in Table 3 and Table 4. In social sciences, adjusted $\mathrm{R}^{2}$ of linear regressions above 0.2 is generally acceptable (Skrabski et al., 2005).

Table 2. T-test results of patient satisfaction between China and Mongolia.

\begin{tabular}{|c|c|c|c|c|c|c|}
\hline & \multicolumn{2}{|c|}{ China } & \multicolumn{2}{|c|}{ Mongolia } & \multicolumn{2}{|c|}{ T test } \\
\hline & Mean & $\mathrm{SD}$ & Mean & $\mathrm{SD}$ & $\mathrm{t}$ & Sig. \\
\hline Gender & 0.65 & 0.48 & 0.53 & 0.50 & 1.730 & 0.085 \\
\hline Age & 22.65 & 7.53 & 23.51 & 9.48 & -0.697 & 0.487 \\
\hline General & 3.91 & 0.37 & 3.39 & 0.38 & 9.554 & $<0.001$ \\
\hline Consideration & 3.07 & 0.44 & 3.29 & 0.44 & -3.506 & 0.001 \\
\hline Specialists & 4.95 & 0.26 & 3.07 & 1.14 & 15.777 & $<0.001$ \\
\hline Explanations & 3.50 & 0.79 & 3.18 & 0.64 & 3.062 & 0.003 \\
\hline Hospitals & 2.86 & 0.53 & 2.69 & 0.43 & 2.374 & 0.019 \\
\hline Convenience of services & 2.17 & 0.57 & 2.67 & 0.50 & -6.558 & $<0.001$ \\
\hline Quality/competence & 2.97 & 0.36 & 2.87 & 0.30 & 2.141 & 0.034 \\
\hline Cost of care & 2.35 & 0.48 & 4.36 & 0.56 & -26.871 & $<0.001$ \\
\hline Prudence-expenses & 3.14 & 0.43 & 3.10 & 0.31 & 0.721 & 0.472 \\
\hline Emergency care & 3.20 & 0.57 & 3.59 & 0.76 & -4.018 & $<0.001$ \\
\hline Payment mechanisms & 2.11 & 0.56 & 2.85 & 0.40 & -10.595 & $<0.001$ \\
\hline Insurance coverage & 3.29 & 0.91 & 3.13 & 0.94 & 1.248 & 0.214 \\
\hline Prudence-risks & 3.10 & 0.82 & 2.99 & 0.88 & 0.924 & 0.357 \\
\hline
\end{tabular}

Table 3. Regression testing results of effects on Chinese patient satisfaction.

\begin{tabular}{cccc}
\hline & Coefficients & $\mathrm{t}$ & Sig. \\
\hline Consideration & 0.521 & 6.857 & $<0.001$ \\
Quality/competence & 0.159 & 2.099 & 0.038 \\
Cost of care & 0.335 & 4.475 & $<0.001$ \\
(Constant) & & 5.105 & $<0.001$ \\
Adjusted R-square & 0.463 & & \\
\hline
\end{tabular}


Table 4. Regression testing results of effects on Mongolian patient satisfaction.

\begin{tabular}{cccc}
\hline & Coefficient & $\mathrm{t}$ & Sig. \\
\hline Hospitals & 0.370 & 4.046 & $<0.001$ \\
Quality/competence & 0.207 & 2.300 & 0.024 \\
Payment mechanisms & 0.349 & 3.822 & $<0.001$ \\
(Constant) & & 1.625 & 0.108 \\
Adjusted R-square & 0.233 & & \\
\hline
\end{tabular}

\section{Questionnaire Survey II}

For the factors which showed significantly important influences on Chinese or Mongolian patient satisfaction in Questionnaire Survey I, we listed some possible reasons which might cause dissatisfaction and revisited the respondents through WeChat and Facebook in China and Mongolia respectively. Respondents were asked to multi-select from the reasons or listed their own reasons of dissatisfaction.

For the sub-scale of quality/competence, among Chinese respondents, six respondents reported the reason of their dissatisfaction was doctors failed to explain to them effectively, six respondents thought the levels of doctors' expertise were relatively low, and six respondents thought the doctors had not a full understanding of health care service, whereas among the Mongolian respondents, only five respondents thought the levels of doctors' expertise were relatively low.

For the sub-scale of cost of care, among Chinese respondents, 59 respondents thought the prices of medicines were too high, 48 respondents thought the charges of examination were too high, 33 respondents thought the prices of medical auxiliary instruments were too high, and 52 respondents thought there were over-treatment in Chinese health care system, whereas among the Mongolian respondents, four respondents thought the prices of medical auxiliary instruments were too high and eight respondents thought there were over-treatment in Mongolian health care system.

For the sub-scale of consideration, among Chinese respondents, 11 respondents thought doctors accepted bribes from patients, 11 respondents thought doctors were careless, and three respondents thought doctors did not respect patients' privacy, whereas among Mongolian respondents, 14 respondents thought doctors were careless and four respondents thought doctors did not respect patients' privacy.

For the sub-scale of hospitals, among Chinese respondents, 13 respondents thought the sanitary in hospitals were poor, seven respondents thought the noise levels in hospitals were high, and two respondents thought the facilities in hospitals were less user-friendly, whereas among Mongolian respondents, three respondents mentioned the poor sanitary, three respondents mentioned high noise levels, and one respondents mentioned less user-friendly facilities.

For the sub-scale of payment mechanisms, among Chinese respondents, 76 
Table 5. Descriptive testing results of patients' dissatisfaction.

\begin{tabular}{|c|c|c|c|}
\hline Sub-scale & Dissatisfaction & Chinese & Mongolian \\
\hline \multirow{3}{*}{ Quality/competence } & Fail to explain effectively & 6 & \\
\hline & Low levels of doctors' expertise & 6 & 5 \\
\hline & $\begin{array}{c}\text { Insufficiency of doctors' understanding of } \\
\text { health care service }\end{array}$ & 6 & \\
\hline \multirow{4}{*}{ Cost of care } & High prices of medicines & 59 & \\
\hline & High charges of examinations & 48 & \\
\hline & High prices of medical auxiliary instruments & 33 & 4 \\
\hline & Over-treatment & 52 & 8 \\
\hline \multirow{3}{*}{ Consideration } & Doctor accept bribes from patients & 11 & \\
\hline & Careless about patients & 11 & 14 \\
\hline & Don't respect patients' privacy & 3 & 4 \\
\hline \multirow{3}{*}{ Hospitals } & Poor sanitary & 13 & \\
\hline & High levels of noise & 7 & 3 \\
\hline & Less user-friendly facilities & 2 & 1 \\
\hline \multirow{3}{*}{ Payment mechanisms } & Long waiting time & 57 & 4 \\
\hline & Complex process of seeing a doctor & 55 & 10 \\
\hline & $\begin{array}{l}\text { First paying charges and then seeing a } \\
\text { doctor (unreasonable procedures) }\end{array}$ & 36 & 7 \\
\hline
\end{tabular}

respondents thought the waiting time was too long, 55 respondents thought the process of seeing a doctor were complex, and 36 respondents though the procedure of first paying fees and then seeing a doctor was unreasonable, whereas among Mongolian respondents, ten respondents mentioned the complex process of seeing a doctor, four respondents mentioned the long waiting time, and seven respondents mentioned the unreasonable procedure (see Table 5).

\section{Discussions}

In general, Chinese patient satisfaction was higher than Mongolian patient satisfaction; this is consistent with the fact that China's health care system is more developed than Mongolia's. In different service aspects, China and Mongolia have their own advantages.

There were similar factors which both influenced Chinese and Mongolian patient satisfaction. Among the factors, quality/competence (involved in the dimension of technical quality) showed significant importance on both Chinese and Mongolian patient satisfaction. The expertise of doctors is one of the dominant factors influencing patient satisfaction (LaVeist \& Nuru-Jeter, 2002). In addition, respondents from both countries concerned financial aspects of health care service system, including cost of care from Chinese respondents and payment mechanisms for Mongolian respondents. Furthermore, according to the analysis of items, Chinese individuals concerned more about whether the 
charges were reasonable, whereas Mongolian individuals concerned more about whether they could receive treatment when they had no enough money to pay the charges.

There were different factors which influenced Chinese and Mongolian patient satisfaction respectively. The factor of consideration (involved in the dimension of interpersonal manner) influenced Chinese patient satisfaction, whereas the factor of hospitals (involved in the dimension of availability of resources); this suggested that Chinese individuals concerned more about doctors' attitudes and services, whereas Mongolian individuals concerned more about the presence of medical resources.

Besides the factor of quality/competence which influenced both Chinese and Mongolian patient satisfaction, for the factors which only showed significant effects on Chinese patient satisfaction-cost of care and consideration, Chinese individuals were less satisfied than Mongolian individuals, whereas for the factors which showed significant effects on Mongolian patient satisfaction-hospitals and payment mechanisms, Mongolian individuals were less satisfied than Chinese individuals; this suggested that individuals felt less satisfied about these aspects of health care service systems, so these factors influenced their overall satisfaction.

For both Chinese and Mongolian individuals, the factors of emergency care and insurance coverage did not show any effects; this was related to the samples to a certain degree. Both samples experienced less emergent situations and serious diseases, so they cared less about emergency care and insurance coverage.

According to the results of Questionnaire Survey II, Chinese respondents expressed their satisfaction more than Mongolian respondents. More Chinese individuals expressed their satisfaction with the issues of high costs of seeing a doctor (including pricey medicines, high examination costs, expensive medical instruments, and over-treatment), long waiting time (including long queueing time and many processes in seeing a doctor), unreasonable procedures (first pay the charges and then seeing a doctor). More Mongolian individuals expressed their satisfaction with the issues of long waiting time (including long queuing time and many processes in seeing a doctor), high costs of seeing a doctor (including expensive medical instruments and over-treatment), and doctors' poor attitudes (including careless attitudes and lack of respect on patients' privacy). Hence, the main problems China and Mongolia face are high costs of seeing a doctor and long waiting time.

Therefore, both China and Mongolia needs to adjust medical charging system in order to satisfy residents' needs for health care service and the socio-economic development level of each country. Both countries need reform in medical treatment system in order to reduce unnecessary queuing and waiting time and develop reasonable treatment processes. Some organizations and hospitals in China are conducting some exploration in the reform of health care system. The online diagnostic system helps reduce on-site queuing and the applications on mobile phones helps reduce the queuing at the cashiers. In addition, Mongolian 
doctors need comprehensive training to improve their service for patients and learn how to establish good relationships between doctors and patients.

\section{Conclusion}

The purposes of this study involved: 1) comparing the differences of patient satisfaction between China and Mongolia; 2) investigating factors influencing patient satisfaction in the two countries; and 3) investigating the reasons why patients felt dissatisfied. This study involved two questionnaire surveys. The first questionnaire survey aimed to explore the first two questions and the second questionnaire survey aimed to explore the last one. 98 valid Chinese responses and 96 valid Mongolian responses were collected in the first survey, whereas the second survey revisited those respondents.

According to the results, Chinese overall patient satisfaction was higher than that of Mongolian. China and Mongolia had their own advantages in different health care service aspects respectively. Chinese individuals were more likely to express their dissatisfaction than Mongolian individuals. Chinese individuals expressed more dissatisfaction with the issues of high costs of seeing a doctor, long waiting time and unreasonable procedures, whereas Mongolian individuals' dissatisfaction focused on the issues of long waiting time, high costs of seeing a doctor and doctors' poor attitudes.

This explorative work provided suggestions for the establishment and improvement of Mongolia's health care system and helped China understand the needs of Mongolia in the health care industry better in order to establish more effective cooperation in the health care field. Future work can be conducted to investigate the cultural influences on other issues related to the health care systems between China and Mongolia.

\section{Acknowledgements}

This study was funded by the Fundamental Research Funds for the Central Universities ZY1706.

\section{References}

A. S. G. (2017). China's Inner Mongolia International Mongolian Medical Hospital Medical Team Carried out Free Clinic in Mongolia, 31 July 2017. http://news.xinhuanet.com/photo/2017-07/31/c_1121410305.htm

Carroll, J. G. (2002). Crossing the Quality Chasm: A New Health System for the 21st Century. Quality Management in Healthcare, 10, 60-61. https://doi.org/10.1097/00019514-200210040-00010

Chinese Academy of International Trade and Economic Cooperation, Investment Promotion Agency of Ministry of Commerce of the People's Republic of China, and Economic and Commercial Counsellor's Office of the Embassy of the People's Republic of China: Foreign Investment Cooperation Country (Region) Guide (2016). Mongolia, 2016, 10-11. http://fec.mofcom.gov.cn/article/gbdqzn/upload/mengguguo.pdf

Fitzpatrick, R. (1984). Satisfaction with Health Care. In R. Fitzpatrick (Eds.), The Experience of Illness, London: Tavistock, 154-175. 
LaVeist, T. A., \& Nuru-Jeter, A. (2002). Is Doctor-Patient Race Concordance Associated with Greater Satisfaction with Care? Journal of Health and Social Behavior, 43, 296-306. https://doi.org/10.2307/3090205

Li, J., Wang, P., Kong, X., Liang, H., Zhang, X., \& Shi, L. (2016). Patient Satisfaction between Primary Care Providers and Hospitals: A Cross-Sectional Survey in Jilin Province, China. International Journal for Quality in Health Care, 28, 346-354. https://doi.org/10.1093/intqhc/mzw038

Ministry of Foreign Affairs of the People's Republic of China (2015). Joint Statement of the People's Republic of China and Mongolia on Deepening the Development of a Comprehensive Strategic Partnership, 11 November 2015. http://www.gov.cn/xinwen/2015-11/11/content_2964503.htm

Skrabski, Á., Kopp, M., Rózsa, S., Réthelyi, J., \& Rahe, R. H. (2005). Life Meaning: An Important Correlate of Health in the Hungarian Population. International Journal of Behavioral Medicine, 12, 78-85. https://doi.org/10.1207/s15327558ijbm1202_5

Tsai, T. C., Orav, E. J., \& Jha, A. K. (2015). Patient Satisfaction and Quality of Surgical Care in US Hospitals. Annals of Surgery, 261, 2-8. https://doi.org/10.1097/SLA.0000000000000765

Ware Jr, J. E., Snyder, M. K., Wright, W. R., \& Davies, A. R. (1983). Defining and Measuring Patient Satisfaction with Medical Care. Evaluation and Program Planning, 6, 247-263. https://doi.org/10.1016/0149-7189(83)90005-8

Yang, T. (2017). Data Shows that China has Maintained Mongolia's Largest Trading Partner for more than 10 Years-Cooperation Enriches the Connotation of Sino-Mongolian Relations, 6 August 2017.

http://paper.people.com.cn/rmrb/html/2017-08/06/nw.D110000renmrb_20170806_1-0 $\underline{3 . h t m}$

You, L. M., Aiken, L. H., Sloane, D. M., Liu, K., He, G. P., Hu, Y., Jiang, X., Li, X., Liu, H., \& Shang, S. M. (2013). Hospital Nursing, Care Quality, and Patient Satisfaction: Cross-Sectional Surveys of Nurses and Patients in Hospitals in China and Europe. International Journal of Nursing Studies, 50, 154-161.

https://doi.org/10.1016/j.ijnurstu.2012.05.003 


\section{Appendix Subscale Items Used in This Study}

Emergency care

1) In an emergency, it's very hard to get medical care quickly. (-)

Convenience of services

2) Places where you can get medical care are very conveniently located.

3) It takes me a long time to get to the place where I receive medical care. (-)

Cost of care

4) The amount charged for medical care services is reasonable.

5) The fees doctors charge are too high. (-)

Payment mechanisms

6) I think you can get medical care easily even if you don't have money with you.

7) Without proof that you can pay, it's almost impossible to get admitted to the hospital. (-)

Insurance coverage

8) Medical insurance coverage should pay for more expenses than it does. (-)

9) I am happy with the coverage provided by medical insurance plans.

Specialists

10) There are enough doctors in this area who specialize.

Hospitals

11) There are enough hospitals in this area.

12) More hospitals are needed in this area. (-)

Quality/competence

13) Doctors ask what foods patients eat and explain why certain foods are best.

14) Doctors are very careful to check everything when examining their patients.

15) Doctors don't advise patients about ways to avoid illness or injury. (-)

16) Doctors aren't as thorough as they should be. (-)

17) Most people are encouraged to get a yearly exam when they go for medical care.

18) The medical problems I've had in the past are ignored when I seek care for a new medical problem. (-)

Prudence-risks

19) Sometimes doctors take unnecessary risks in treating their patients. (-)

Explanations

20) Doctors hardly ever explain the patient's medical problems to him. (-)

21) Doctors cause some people to worry a lot because they don't explain medical problems to patients. (-)

Consideration

22) Doctors always treat their patients with respect.

23) Doctors never recommend surgery (an operation) unless there is no other way to solve the problem. 
24) Doctors always do their best to keep the patient from worrying.

25) Sometimes doctors make the patient feel foolish. (-)

26) Doctors respect their patient's feelings.

Prudence-expenses

27) Doctors always avoid unnecessary patient expenses.

General satisfaction

28) I'm very satisfied with the medical care I receive.

29) Most people receive medical care that could be better. (-)

30) The care I have received from doctors in the last few years is just about perfect.

31) There are things about the medical care I receive that could be better. (-)

Items marked with (-) define unfavorable attitudes; their final scores should be recorded by the differences between six and their raw scores. 